\title{
Migraine and Neurological Disorders Comorbidity-Consideration of Sinus Hypoxic Nitric Oxide Theory for Migraine
}

Senanayake Mudiyanselage Rathnasiri Bandara ${ }^{1 *}$, Jayarathna DGAI ${ }^{1}$, Sampath Thenakoon ${ }^{2}$ and Kithsiri Jayanath Senananayaka ${ }^{3}$

${ }^{1}$ Teaching Hospital Kandy, Kandy, Sri Lanka

${ }^{2}$ Department of Community Medicine, University of Peradeniya, Sri Lanka

${ }^{3}$ Department of surgery, Faculty of Medicine, University of Rajarata, Sri Lanka

\begin{abstract}
Migraine is an extremely common disorder and has co morbidity with many neurological illnesses. After reviewing the neurophysiological and biochemical basis of the research findings and hypotheses of migraine and other neurological disorders I present to the best of my knowledge the first para nasal sinus nitric oxide mediated neurobiophysiological explanation for many neurological disorders. The etiology of neurological illnesses is mainly due to neurotransmitter imbalance, neurodegenerative changes acute and chronic inflammation, effects of hypo and hyper endothelial and neuronal NO levels and genetic predisposition. According to this para nasal sinus nitric oxide based description those effects are mainly brought on by the sinorhinogenic impulse distribution of the central nervous system except genetic predisposition. Moreover, avoidance of the central neuronal influence and stress to the brain in early childhood or young age caused by migraine would help to prevent the progression or aggravation of the neurological illnesses. Indeed this article explains a new pathophysiological initiation between sino rhinogenic nitric oxide effects and neurological disorders and provides an etiologically important Neuro vascular impulse generating pathway to cause or aggravate neurological disorders. Therefore the patients who are clinically suspected of having migraine headache and neurological disorders or along with susceptible neurological disorders should receive comprehensive sinorhinological examination and evaluation based on the sinus hypoxic nitric oxide phenomena. A standard surgical and medical management of migraine that links with the sinus hypoxic nitric oxide theory are suggested to be used for even neurological disorder as a new treatment of neurological illnesses and to prevent the dysfunction of central specific neural circuits.
\end{abstract}

Keywords: Migraine; Neurological disorders; Sinus hypoxic nitric oxide theory

\section{Introduction}

Migraine is a common neurological disorder and affects about $15 \%$ of people in developed countries [1], which is co-morbid with many neurological illness such as stroke [2], epilepsy [3], motion sickness [4], vertigo [5], balance disorder [6] and benign intra cranial hypertension [7], Narcolepsy [8]. Therefore revealing the exact pathophysiological mechanism between them is of great value in the management of both disorders. Many explanations have been suggested for pathogenesis of the co-morbidity.

Among them cerebral ischemia due to migraine is caused by Cortical Spreading Depression (CSD) as a direct cause. Moreover endothelia dysfunction, overuse of anti-migraine drugs and genetic factors are proposed as the main indirect causes [9]. For epilepsy it has been proposed that the connecting point is CSD in addition to genetic components [10]. The neuro pathological explanation for migraine co morbid with neurological illnesses that is due to shearing of common receptors, neuronal tracks and some pathology of blood vessels has been put forwarded. However none of these facts can explain well what the exact common mechanism is which underlines the migraine and neurological co-morbidity so that it can be treated using the control of migraine pathophysiology. This was mainly because the exact common pathophysiology for migraine has still uncertain. However the Hypoxic Nitric Oxide Theory [SHNOT] for pathophysiology of migraine [11] can be considered as an additional cause or aggregative pathophysiological mechanism and thereby introduce a new medical and surgical approach for the management of such neurological illnesses. These evidences are emerging that migraine is not solely a headache disorder. Moreover this review will summarize the salient evidence suggesting a comorbid association between migraine, neurological disorders and the hypoxic nitric oxide theory for their comorbidity.

\section{Sinus Hypoxic Nitric Oxide Theory for Migraine}

To explain the scientific background of the topic, research findings on pathophysiology of migraine, neurological disorders and para-nasal and nasal Nitric Oxide (sNO) [12] in human beings as well as animals were reviewed. In this article Sinus Hypoxic Nitric Oxide Theory (SHNOT) is mainly considered. It is hypothesized that diffused sNO $(\mathrm{dsNO})$ in the nasal and para nasal mucosa is a main causative and an initiative molecule for migraine headache. This has been used here to explain the association between migraine and neurological disorders.

Moreover the SHNOT explains that diffused NO cause's repetitive or intermittent activation of the peripheral trigeminal sensory nerve and induces shear stress in the mucosal blood vessels initiating the neurovascular pathophysiology of migraine attack [11]. The relative hypoxia to paranasal sinuses causes to induce increased production of sNO [13].The nerve impulses of the trigeminal sensory nerve induced by $\mathrm{sNO}$ are projected at trigeminal nucleus caudal is to the central nerve system. According to the hypothesis Cortical Spreading Depression (CDS) is brought by low brain magnesium, abnormal release of excitatory neurotransmitter and low mono aminergic $5 \mathrm{HT}$ projection

${ }^{*}$ Corresponding author: Senanayake Mudiyanselage Rathnasiri Bandara, 11/1 "ISURU" Gannoruwa road, Peradeniya, Sri Lanka, Tel: +94714453646; E-mail: rathnasirib@yahoo.com

Received April 29, 2014; Accepted September 25, 2014; Published September 27, 2014

Citation: Bandara SMR, Jayarathna DGAI, Thenakoon S, Senananayaka KJ (2014) Migraine and Neurological Disorders Comorbidity-Consideration of Sinus Hypoxic Nitric Oxide Theory for Migraine. J Neurol Disord 2: 175. doi:10.4172/23296895.1000175

Copyright: (@ 2014 Bandara SMR, et al. This is an open-access article distributed under the terms of the Creative Commons Attribution License, which permits unrestricted use, distribution, and reproduction in any medium, provided the original author and source are credited. 
from the dorsal raphe due to the consequence of the shear stress and the influence of the trigeminal central neuronal impulses [11]. Thus it is named sinus hypoxic nitric oxide theory (SHNOT) for migraine. The existence of its pathophysiology in human beings including migraine is named here as sinus hypoxic nitric oxide phenomena (SHNOP) opening a new direction in surgical and medical management of the neurological illnesses.

\section{Evidence based Supportive Studies for SHNOT for Migraine}

This hypothesis can be tested with the currently available NO research methods and the standard surgical and medical management and is supported by the strong scientific evidence of important research findings as follows.

\section{Physiological and biological roles of NO}

$\mathrm{NO}$ as a potent vasodilator and neurotransmitter has shown its high ability to diffuse through the cell membrane $[14,15]$ and it can repeatedly cross cell membranes during its half-life [16]. Unlike other neuro transmitters NO can bind directly to guvanyl cyclase in the cytoplasm and activates it [17]. Moreover, NO appears to carry information on neural activity and release other neurotransmitters such as CGRP, glutamate, n NO, etc. across the synaptic junction [1820].Therefore diffused sNO would have similar property to give rise neuronal impulse and vascular dilatation within nasal and para nasal sinus mucosa in susceptible conditions.

\section{Recovery from migraine by reducing the synthesis of sNO}

Hypoxia is the potent inducer of sNO synthesis [21],which can be caused by various factors such as inflammation, anomalies, female hormones, pathological and environmental factors. These in turn cause or contribute to nasal and para nasal edema or inflammation leading relative hypoxia to the para nasal sinuses [11]. In this line, an approach of reliving hypoxia would cure migraine or reduce the number of migraine attack according to the SHNOT/P. This argument is supported by two successful surgical studies as follows. There were $78 \%$ of totally asymptomatic migraine patients [22-24] after siniorhinological operation. Furthermore it has been shown that all $75 \%$ of patients with migraine were free of symptoms and $20 \%$ had improved by $50 \%$ with duration and frequency of the attack after sinus hypoxia reliving similar surgical approach [25].

\section{Intranasal treatment for acute migraine attack}

According to the hypothesis sNO can generate peripheral trigeminal impulse begun at intranasal and sinus cavity. In this line the neuronal impulse could be stopped by administration of intranasal NO scavenger and local anesthetics. The treatment with local anestheticsintranasal lidocane [26] and cocaine [22-24] and NO scavenger -intranasal hydroxyl cobalamin [27] and sumatriptan [28]-has been shown that they were effective in relieving acute migraine.

\section{Intranasal gases can stimulate trigeminal nerve pathway}

It has been shown that application of a few gases into the nasal cavity could generate trigeminal neuronal impulse though NO has not still been used for the test. For instances of MRI changes similar to trigeminal stimulation in migraine patients could be observed following the intranasal administration of nociceptive stimulus using the application of ammonia $\left(\mathrm{NO}_{4}\right)$ [29] and sensory stimulus using $\mathrm{CO}_{2}$ [30]. When these gases are compared with the physiological and biological role of sNO it would directly and easily stimulate neurovascular compartment of the mucosa generating trigeminal impulses and the shear stress in the blood vessels.

\section{sNO can diffuse through respiratory epithelium}

Furthermore it has been proven that sNO could diffuse through respiratory epithelium in the lung and it can dilate lung blood vessels and increase oxygen absorption [31]. In this line, it is obvious that sNO could diffuse through the respiratory epithelium in the nasal and sinus cavities and activate the neurovascular compartment in the mucosa.

\section{Evidences of Migraine and other Neurological Disorders Co-morbidity}

The relationship between migraine and neurological disorders has been repeatedly reported in many publications without clear outcome and a clear plan of the proper management of the co morbid influences. There for the exploration of actual pathophysiology between migraine and neurological disorder co morbidity is important. In addition to those, in this review following five sub topics are firstly going to be discussed so that one could widely understand the co-morbidity between migraine and neurological disorders.

\section{Epidemiological evidence}

It is not uncommon that migraine coexists with neurological disorders because of the high prevalence of migraine. However there is a strong association with striking similarities existing between the epidemiological characteristics of migraine and some neurological disorders. In fact a particular association between epilepsy and basilar type of migraine has been found $[32,33]$. In addition migraine and epilepsy has also been reported to occur with migralepsy and hemicranias epileptic [34,35]. Moreover the research data indicates that migraine and epilepsy are strongly associated, independent of seizure type, etiology, age at onset, or family history of epilepsy. For instance migraine to age 40 was $24 \%$ in profanes with epilepsy, $23 \%$ in relatives with epilepsy, and $12 \%$ in relatives without epilepsy. This pattern of results is indicated that it is inconsistent with the hypothesis of a shared genetic susceptibility to migraine and epilepsy [36].

On the other hand, where the causes for migraine and stroke comorbidity is concerned, the genetic component, over use of antimigraine drugs, cardiovascular risk factors and migraine ischemic stroke pathway has been proposed by some authors [37,38]. However about half of the ischemic stroke in young adults that have no detectable cause is around $0.5 \%$ to $1.5 \%$ of all ischemic stroke $[39,40]$. In narcoleptic patients migraine prevalence was twofold to fourfold increase and it was amounted to $44.4 \%$ in women and $28.3 \%$ in men $[40,41]$. When the most common vascular symptoms motion sickness is investigated, it was reported by $30 \%$ of patient with migraine [4]. Thus these epidemiological evidence indicate that pathophysiological pathway between the neurological disorders and migraine are similar or interrelated which must be considered more rather than the high prevalence of migraine among neurological disorders.

\section{Pharmacological evidence}

Seizure generation and spread is mediated by synaptically released glutamate acting on AMPA receptors, whereas triggering of CSD depends on NMDA receptors [42] and spread does not require synaptic transmission. This is because some antiepileptic drugs (e.g. sodium valproate, topiramate) prevent the occurrence of migraine attack [43]. This supports the view that neuronal hyper excitability is an initiating event in both conditions. In addition tricyclic antidepressants used in migraine prophylaxis cause to reduce seizure threshold leading 
to risk of seizure attack in some epileptic patients. On the other hand stroke associated with migraine treatments such as ergots or trip tans is rare, and but it is usually associated with special circumstances such as concomitant thrombogenic conditions [44]. In addition the effects of over use of migraine specific drugs such as triptans and ergotamine or hormonal contraceptive drugs have associated with an increased risk by ischemic stroke events $[32,45]$. These evidence reveal that anti migraine drugs can made the comorbid relationship other than their pathophysiological connections.

In migraine prophylaxis cinnarizine (CIN) -L-type calcium channel blocker has early onset effects [37,46-48] and it can directly inhibit vestibular hair cells stimulation and also has antihistaminic actions [49]. Therefore, CIN is a good for treatment of migraine with vertigo. Moreover tricyclic antidepressants or beta-blockers has been reported that they are highly effective in nonspecific migraine-associated vertigo $[37,49]$. Nitric oxcid synthase inhibitors could inhibit the endothelial NOS and neuronal NOS to attenuate spontaneous migraine attack [49]. Then the propagation of nerve impulses through the trigeminal nerve and vascular spasm through the arterial system are abolished. Furthermore, NOS inhibitors have been used to improve headache pain scores in spontaneous attacks of migraine [50]. Moreover it has been known that NO has involved in many neurological disorders [18]. These highlight that the comorbidity could arise through molecular and receptor level.

On the other hand as there are some cognitive difficulties in Multiple Sclerosis (MS) patients, cognitive function reducing anti migraine drug like topiramate and flunarizine should be avoided in use [51]. In addition migraine prophylaxis drug like beta-blockers induces depression. Therefor the drugs are not good for both migraine and MS patients who are risk in depression [52]. However as tricyclic anti depression relives neurogenic pain that can be used in the two disorders. These pharmacological evidences reveal that some of the pharmaco molecules and receptor level evidences support for the migraine and neurological disorders comorbidity. But the drug interaction in those condition should be considered seriously when the association is strong and harmful effects.

\section{Genetic and acquired mal function of brain tissues}

Migraine and epilepsy may be due to common genetic and molecular substrates e.g. familial hemiplegic migraine [53]. Furthermore some neurological illnesses are increasingly linked with malfunction of brain tissue that affected by both genetic and environment influences. On the other hand both migraine and stroke are found to be in some inherited disorders such as hereditary endotheliopathy and cerebral retinal vasculopathy [54]. In addition it has been mention that migraine and Multiple Sclerosis (MS) has shared genetic or environmental factors leading to a higher likelihood of both conditions occurring in the same individual. Moreover narcolepsy may be brought by the hypocretin (orexin) receptor 2 gene which causes genetic narcolepsy in several animal species and in humans $[55,56]$ and associates with migraine. Interestingly according to SHNOT migraine can run through family via genetics that may mainly contribute to make the nasal and paranasal anatomy [19] that could be corrected easily rather than other noncorrectable genetic influence.

\section{Objective investigative evidences}

There are a few successful siniorhinological surgical studies that relive migraine headache totally and partially [22-25] but it is not investigated for the comorbidity. Following case report as objective investigative evidence would help to understand the comorbid influence and therapeutic value. A post-surgical follow up of a 31 years old male patient with neurological disorders who had under gone a sinorhinologial surgery was reported [57] as follows He was diagnosed as having migraine with aura and had history of increased in number of migraine attack for a period two years. This time he had presented to medical ward with history of left side weakness of body, reduced hearing and vision of that side for one day and sever migraine head ache for two days. However he had been investigated for left side weakness of body and sinorginological cause for headache because his symptoms of headache were not response to the existence drug management. His blood tests for inflammatory vascular disease were normal and CT scan was found to have an infarction of right side posterior limb of internal capsule in the brain. In the paranasal sinus view of the CT there were hyper trophy of inferior turbinate, right side small nasal cavity and nasal septal deviation to right side (Figure 2). Then under adequate protection of prevention of further infraction he was later undergone a surgical procedure for sinorhinological pathology for head ache, which include a reduction of the bilateral hyper trophy of inferior turbinates, resection of anomalies in the nasal cavity and septoplasty. After the surgical treatment, his migraine attacks were subsided without any anti-migraine medication. Moreover no headache was identified after he was followed up for one year and the neurological weakness also improved with time. This data has proved that the surgical approach would relive the hypoxia and reducing the $\mathrm{NO}$ absorptive surface areas. Furthermore it may be proposed as a successful for treatment for migraine and prevention of further deterioration of stroke. In addition this right side infarction and more sinus hypoxic anomalies in the right side of the CT scan may direct us to think of a correlation between SHNOP and the infraction. According to this SHNOT hypothesis it can be suggested that more sinorhinogenic impulse from right side of paranasal sinus would develop thrombosis of the small arteries that supply to the area of internal capsule giving rise the infraction. By enlarge this finding supports migraine and stroke co-morbidity and rhinological therapeutic value for the neurological illnesses.

\section{Neuro pathophysiological evidence}

The pathophysiology of migraine predicts that there are central neuronal dysfunctions including, increased grey matter changes in some regions and decreased in others, dysfunction of neurotransmitter track, altered pain modulatory system, neuronal degeneration in the central nervous system and changes of brain blood flow and vascular integrity. These may indicate that the association could badly affect to the neurological illnesses. In addition in this sub topic, acute and chronic stress, abnormal sleep pattern, central sensitization, neuronal nitric oxide $(\mathrm{nNO})$ roles in neurological disorders are going to be explained on migraine pathophysiology. These would help once to understand that one way of association of migraine and neurological illnesses is due to more pathological effects of the illness rather than its high prevalence.

Dysfunction of main neurotransmitter projections: Dysfunction of main neurotransmitters could be explained due to the possibility of the central neuronal effect caused by migraine pathophysiology [58]. According to some migraine theory, the nociceptive impulses of trigeminal second order neuron are modulated by descending cortical inhibitory systems [59] impinge with serotonin neuron [6063 . As a result of that it leads to deplete central serotonin causing dysregulation of central serotonin levels [64]. In fact serotonin deficiency is found as increased pain sensation in many neurological disorders [65].Interestingly serotonergic neurons in the central neuron system impinge on many other neurons such as central cholinergic, dopaminergic, noradrenergic and GABAergic neurons [66]. In addition 
deficiency of serotonin causes to release the brakes on dopamine (DA) and noradrenalin (NA) neuron held by serotonin leading to develop dysfunction of DA, glutamate and NA neurotransmitter tracks [62,63]. It means that dysfunction of the serotonergic track caused by migraine pathophysiology that in turn affects those neuronal connections or neuro circuits linking with the pathology of other neurological illnesses.

Acute and chronic stress to the central nervous system: This can be caused by migraine headache itself. For instances sympathetic hypo function, hyper activity of the cranial parasympathetic nerve, lower levels of noradrenalin in the Extra Cerebral Spinal Fluid (ECF) would emphasize the association of stress due to migraine in the $[67,68]$. Moreover increased urinary nitric oxide metabolites and lipid peroxidation in migraine patients reveal that there was an increase in the availability of oxidative stress [69]. Therefore these changes due to the stress could alter central neurotransmitter (DA, NA, 5HT) levels [70] contributing to induce or aggravate neurological disorders.

Abnormal sleep pattern: Pathology of migraine may affect the sleep cycle in different ways such as lack of sleep, somnambulism, night terror and narcolepsy [71]. Moreover hypothalamic involvement in migraine has been observed in disturbance to sleep, alertness and wakefulness [72]. Interestingly, abnormal sleep cycle contributes to alter the functions of the 5-HT nerve of the dorsal raphe nucleus and involves DA neurons in the ventral segmental area, nucleus accubens and forebrain [73]. Furthermore glucocorticoid, prolactin, melatonin [74] and orexin [75] in the central nervous system have been altered by the sleep disorders induced by migraine. On the other hand these changers can also alter the sleep cycle [76] leading to increased wake fullness, or reduction of sleep that can be observed in and cause to aggravate neurological disorders.

Central sensitization: This condition of migraine could be brought by the continues or intermittent trigeminal sensory nerve impulses in migraine, which can generate strong action potential in the central nervous system and develops central sensitization [77,78] which in turn facilitates to persist chronic migraine and could be a factor to aggravate existence neurological disorders.

Hyper excitability and enhanced responsiveness of the cerebral cortex: This may occur in both migraine with aura and migraine without aura due to alteration of energy metabolism, high plasma concentration in ion calcium, low brain magnesium, abnormal release of excitatory neurotransmitter and low mono aminergic 5HT projection from the dorsal raphe $[79,80]$. The latter three mechanisms have already been explained in SHNOT/P. On the other hand higher excitability in brain would favor CSD. The neuronal and glial cells despoliation in CSD initiate the release of neural proteases which can affect abnormal brain function [81,82]. Glutamate release could be brought about by elevation of astrocyte internal calcium by the influx of $\mathrm{Ca}^{2+}$ into neuronal tissue [82]. Thus it contributes to lower threshold of spontaneous depolarization and cortical spreading depression may lead to epileptic attack in genetically susceptible patients or secondary neuronal damaged patients. The neuronal activation generated by CDS further decreases the threshold in the epileptic focus, increasing the risk of seizures. Release of metalloproteinase has been implicated following CSD in migraine $[81,82]$ which may damage vascular basement membrane. This could be suggested to give the risk of stroke.

Excesses production of neuronal nitric oxide (nNO): $\mathrm{nNO}$ has many roles in neurological disorders. In fact, in the pain mechanism of migraine, there is increased $\mathrm{n}$ NO production involving both migraines with and without aura $[83,84]$. Neuronal nitric oxide synthases (n NOS) produces $n$ NO almost exclusively after the activation of NMDA receptors and is a calmodulin-dependent process preceded by the elevation of intra cellular $\mathrm{Ca}^{+2}$ concentrations [85]. Interestingly serotonin is able to activate $\mathrm{nNOS}$, leading to the generation of reactive oxygen species (ROS) and NO production. n NO metabolites such as $\mathrm{ONOO}^{-}$is a causative factor in neurotoxicity $[86,87]$ (Figure 1 ). Thus SHNOP or migraine pathology could involve in the pathology of the many neurological illnesses with respect to the degenerative changes or toxic effect in the neuronal system due to the effect of peroxy nitrate toxicity. It also has been found that peroxy nitrate involves in the pathology of Parkinson's disease and amyotrophic lateral sclerosis [18]

Shear Stress in the blood vessel: This phenomena due to migraine pathophysiology may induce ATP-independent transient nitric oxide release from vascular endothelium [88] where NO can be made 10 to 40 fold more endothelial NO (e NO) than needed to activate guanylate cyclase. Moreover such e $\mathrm{NO}$ can react with $\mathrm{H}_{2} \mathrm{O}_{2}$ leads to formation of peroxy nitrite which is toxic molecule affecting biological component and may cause to cells necrosis, organ damaged and inflammation $[18,88,89]$. Thus in chronic migraine attack ,there may be a higher level of formation of peroxy nitrite which may damage the arterial endothelium and even smooth muscles cell in vulnerable and susceptible area of the blood vessels [90-92]. Finally its toxic damage would contribute [18] to develop vascular aneurism or stenosis of cranial arteries. At the end they may tend to rupture the blood vessels with or without hyper tension or develop infraction in the arteries. This may lead to nerve palsy when a small artery supply to single nerve or a massive stroke if larger arteries are affected.

A decreased level of plasma melatonin: A low level melatonin of the migraine population has been observed [93]. In fact melatonin secreted mainly by pineal gland involves in an important actions such as reducing and protecting from a direct and indirect oxidative damage. Thus it has the ability to protect neuronal cells against apoptosis [94,95]. Furthermore melatonin has an anticonvulsant and depressive effects [95]. It means that migraine patients are more susceptible to develop oxidative damage, neuronal track dysfunction, hyper excitability brain and lower seizure thresholds due to decreased level of plasma melatonin.

\section{The Mechanisms Contributed by Migraine Pathophysiology for Neurological Disorders}

The pathophysiology of migraine has revealed that migraine is not just a headache disorder and is a complex neurological disease. Moreover the biological and physiological changes in migraine pathology as describe above can influence on central nervous system. This would make the path way between migraine and other neurological disorders comorbidity.

\section{Epilepsy}

Epidemiological studies demonstrate that epilepsy and migraine are co morbid conditions [96]. Basic mechanisms of epilepsy are proposed in number of ways such as chromosomal disorder, traumatic brain injury, reduction of $\mathrm{N}$-acetyl aspartate/creatinine ratio in the hippocampus epilepsy, reorganization of cortical circuits (barrel circuits) in response to cortical lesions, cortical malformation, hyper cortisolemia, astrocytes contribution to neuronal hyper excitability ,electrolytic imbalance and hypoglycemia, release of neurotransmitter glutamate (e.g.-gliomas) causing disruption of ion homeostasis and hyper excitability in neighboring tissue [84]. In this line it is evident that migraine can be suggested that its pathology can facilitate as a trigger factor for epilepsy such as hyper corticosolemia, astrocytes contribution to neuronal hyper excitability, electrolyte imbalance, 


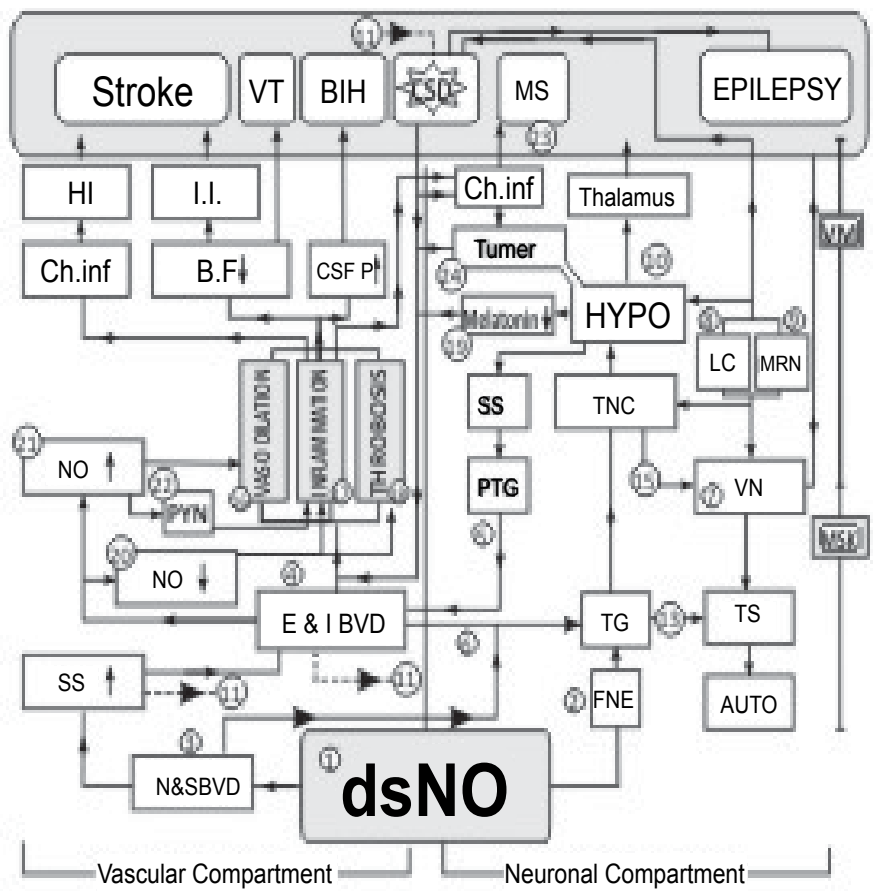

Figure 1: Pathophysiology model of neurological disorder based on dsNO.

dsNO may activate free nerve ending [FNE] (2) of trigeminal nerve and dilate the blood vessels in the nasal and sinus cavities [N\&S BV]. (3) The shear stress[SS] induced by the vasodilation brought on by ds NO spreads as a wave or spasm to extra cranial and intra cranial blood vessels [IC\&ECBV] (4) including labyrinthine arties which also affected by peptide released by parasympathetic innervation[PSI] (5) through trigeminal vascular system. Perivascular nerves of those blood vessels are activated by the vascular dilatation and neurogenic inflammation induced by the PSI and project their impulses to trigeminal nucleus cordalis [TNC] (6) via trigeminal ganglion [TG] where the impulses of the free nerve endings also reache. TG projects (7) the impulse to vestibular nuclei [VN] and TNC where the serotogenic [MRN] (8) and noradrenergic [LC] (9) pathways imping and influence. These projections may contribute to trigger migraine partway and modulate pain pathway. In addition this leads to develop dysfunction of serotonergic pathway that projects impulses to (10) the hypothalamus and the cortex and contributes to give rise cerebral spreading depression [CSD]. Moreover there is a hypothetical contribution from hypo hypomagnesemia occurs as a results of (11) the vaso spasm or SS (--- - dotted line) in the cranial arterial endings, which may act synergistically with serotonin dysfunction at cerebral cortex to (12) give rise CSD. The trigeminal afferent impulse for the dilated blood vessels (13) reach directly to Nucleus tractussoliterii (14) which triggers automatic response and to the VN (15) through TNC affecting balance in the body. The conjugated inter connection between these nucleus and cortical nerve circuits may contribute to give rise motion sickness [MSI] in patient with migraine. On the other hand vestibular migraine [VM] could be taken place through trigeminal vestibular pathway, effect of mono aminergic processing at vestibular area, dilatation of labyrinthine vessels and involvement of cerebral cortex. Dysfunction of seratogenic track leads increased glutamate and calcium ion activity in the neuronal cells contributing to cause hyper excitability of the brain. Both CSD and hyper excitability would contribute reduce the seizer threshold for epilepsy. On the other way CSD tending to alter vascular permeability gives rise to vasodilatation(16), inflammation (17), coagulation and thrombosis (18) which are contributed by extraversion of excaudate by trigeminal parasympathetic nerves, vasospasm in SS and low melatonin level (19) in migraine patients. Furthermore lower production of e NO (20) could be due to exhaustion of nitric oxide synthase (NOS) enzyme in recurrent and chronic migraine, which contributes to increase the coagulation of blood and inflammatory effects. Conversely higher production of e NO and $\mathrm{n}$ NO (21) in migraine patents could give vasodilatation and a toxic product NO metabolite like Peroxy Nitrite [PYN] (22) which in deed induce neuro vascular damage pathways through inflammation and cellular toxicity. Thus all these contribute to reduce cortical blood flow leading to ischemic infarction [I I] in arterial territory and Venous Thrombosis (VT) in venules and Venus sinuses of the brain. In this light chronic pathological state will be suggested to be developed into chronic damage to vascular system tending to hemorrhagic infarction [H I] and to chronic inflammatory damage to (23) the central nervous system may be suggested to occur multiple sclerosis (MS). On the other hand the cerebral spinal fluid [CSF] pressure is raised due to out flow track obstruction due to the thrombosis and the coagulation effects and increased production of CSF due to the inflammation. Both effects are suggested to contribute to develop benign intracranial hyper tension [BICH]. The tendency to develop pituitary tumor $[\mathrm{PT}]$ is proposed here by transfusions of inflammatory substance and excess production of e and $\mathrm{n}$ NO and their metabolites in migraine attacks contributing the high blood flow to the gland (24).

release of glutamate. On the other hand vascular thrombosis or lack of blood flow due to CSD in migraine attack might lead to ischemic infraction to cerebral tissue. This may in turn contribute to develop epilepsy due to cortical lesion.

\section{Infarction and hemorrhage}

Migraine headaches could be precipitated by cerebral ischemia, initially highlighted a possibly association between migraine and cerebrovascular disease. In migraine induced infarction, it is mainly supposed that the consequences of CSD of migraine or chronic migraine with aura are a direct cause leading a sluggish blood flow in major intracranial vessels and neuronaly mediated vasodilatation. Furthermore CSD results in altered vascular permeability, driven in part by activation of matrix metallo proteinases [97] and hypo perfusion of small penetrating arteries [98] which could lead to hypoxic brain injury.

In addition neurogenic inflammation, resulting from CSD and exogenous activation of the trigemino vascular system, causes the release of inflammatory cytokines, neuropeptides (e.g., calcitonin generelated peptide, substance $\mathrm{P}$ and neurokinin $\mathrm{A}$ ), and extravasations of plasma proteins (bradykinin and prostanoids) [99]. Thus migraine induced infraction could be caused by predisposing to coagulopathy such as intravascular thrombosis by up regulation of adhesive molecules and dehydration hyper viscosity, and vasodilatation caused by release of vasoactive substances such as activation of cytokines, vasoactive peptide and e NO [100]. Moreover it could be proposed that cytotoxic 


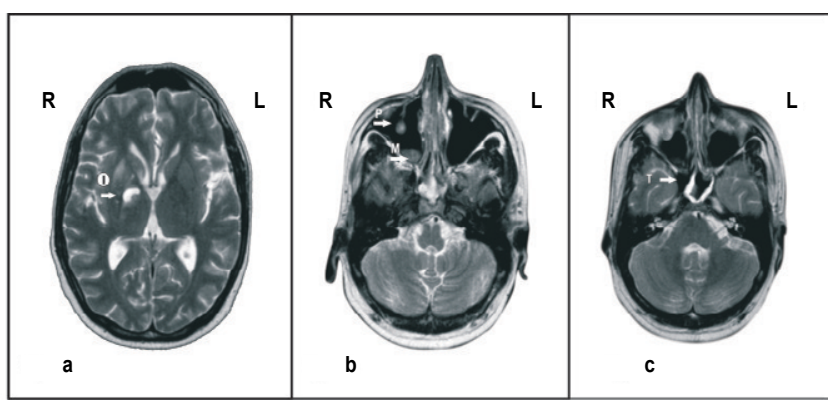

Figure 2: a, b and c: T/w axial section of brain show an infarction involving genu and posterior limb of right internal capsule with ischemia of head of right caudate nucleus and adjacent portion of lent form nucleus. In addition paranasal sinuses view indicates the spheroidal mucosal thinking $[T]$ and sinusitis, polyp[p] in the right maxillary sinus nasal septal deviation and $B / L$ hypertrophy of inferior turbinate (latter two are not in the figure).

cell damage and gliosis caused by intra vascular calcium accumulation or glutamate release could be induced by frequent aura due to CSD in migraine patients.

On the other hand, in this back ground it can be suggested here that not only stroke due to ischemic infarction but also hemorrhagic infarction that could be happen due to migraine. It may be because the inflammatory process in chronic migraine attack may lead to chronic inflammation in the cranial blood vessels. Then such affected vessels would be susceptible to rupture in vulnerable status. In fact 15 to $30 \%$ of all stroke patients would be expected to have a past history of migraine [101]. Therefore it may be strongly suggested here that child and adult hood migraine should be paid a great attention because they will be more susceptible to give a risk in hemorrhagic or infarction stroke in young age as well as old age. However other causes of stroke must be excluded before making a diagnosis of complicated migraine. Moreover it should be considered that the neurological deficits in stroke or infarction should mimic the prior migrainous symptoms and follow a typical attack. On the other hand there are the variants of migraine such as hemiplegic migraine, basilar migraine, ophthalmologic migraine that may be due to relevant vascular arterial pathology induced by the pathology.

\section{Facial pain syndrome}

In this syndrome, pain in the facial area is often the presently complaints as it is associated with signs and symptoms of one or several cranial nerve lesions. There are many causes for facial pain syndrome such as inflammatory in origin, followed by neoplastic or vascular or infection or auto immunological disorder [102]. A common facial pain disorder is bell's palsy is brought by inflammatory, infections, compressive and infiltrative causes [103]. Thus in this line migraine can also be proposed to be one cause for facial pain syndrome because the pathophysiology of migraine tends to give neurogenic inflammation and susceptible to develop infarction induced demyelination leading to give rise the neurological illness such as cranial mono neuropathies.

\section{Parkinson's disease}

The cause of Parkinson's disease is also exactly unknown and loss of cells in the substantial nigra is proposed as a cause for Parkinson's disorders [104]. According coagulopathy of migraine it can strongly be suggested here that CSD can contribute does develop thrombosis in the blood vessel leading to develop infarctions due to prolong low blood flow to the substantial nigra and toxic neuronal damage. However some findings of Parkinson's disorders may suggest a different role of the dopaminergic system in migraineurs with and without a family history of migraine [105].

\section{Benign Intracranial Hypertension (BICH)}

It was observed that there was a link between migraine and idiopathic intracranial hypertension [106]. In this condition, there is without any mass lesion or of hydrocephalus but patient will be raised intracranial hypertension due to cranial out flow obstruction as direct cause such as cortical venous thrombosis [107] or increase CSF secretion [108] and as indirect causes such as obesity, oral contraceptives, nalidixic acid, steroid withdrawal and endocrine dysfunction [109]. Chronic migraine or SHNOP can be suggested here as a cause or trigger factor for $\mathrm{BICH}$ because it may contribute to develop venous thrombosis and increase the inflammatory substances.

\section{Primary Empty Sella Syndrome (PES)}

PES is an uncommon developmental disease that was assumed to be occurred spontaneously and is characterized by herniation of subarachnoid space within the the sella turcica of the pituitary gland [110]. In addition to PES syringomyelia that was proposed due to the loss of shock absorbing capacity of the cisterna magna and subsequent increase of central canal wall pressure leads to syrinx formation in patients with Chiari I malformation $[111,112]$ that can occur due to several steps after obstruction of CSF outflow within sub arachnoid space [113]. The same pathology for BICH could be applied here to explain the increased CSF pressure to give rise or as a contributory cause for the neurological disorders.

\section{Cerebral Venous Thrombosis (CVT)}

This could be brought by dehydration, inflammation, coagulation disorders, head trauma and malignant meningitis which lead to impair cerebral spinal fluid drainage [114]. Thus such patients are presented with headache, papilledema and impaired consciousness [114]. The inhibition of platelet aggregation and thrombosis formation, prevention of inflammation and oxidative damage and enhancement of endothelium dependent vaso relaxation are impaired [18,115] when there is low or defect in e NO production in cranial venues compartment. It could happen in increased number of attack and prolong attack of chronic migraine patients because of exhaustion of $\mathrm{e}$ NO production or reduce bio availability of e NO. Moreover the peroxy nitrite production in the arterial compartment in susceptible migraine patients may also damage to the vascular endothelium and smooth muscles cells [116], up regulation of adhesive molecules in endothelial cells, neutrophil adhesion and stimulating platelet aggregation [18]. In this line the coagulate pathology of migraine can be suggested here to have more susceptible to aseptic and non-malignant CVT.

\section{Multiple Sclerosis (MS)}

The pathophysiology of migraine has already been hypothesized to involve in multiple sclerosis (MS) through CSD during migraine aura which cause to increase permeability to circulating $\mathrm{T}$ cells through the blood-brain barrier, and thereby allow to become sensitized to myelin [117]. On the other hand as there are some changes in cytokine expression during the CSD that may predispose to autoimmune disease in the CNS. Thus both mechanisms are capable to induce chronic CNS inflammatory lesions to develop MS [118].

\section{Motion sensitivity}

Motion sensitivity is reported by $30 \%$ of patient with migraine 
which is the most common vascular symptoms of migraine. It has been proposed that the pathophysiology occurs in migraine brain stem nuclei which influence sensory inputs, cranial blood vessels trigeminal nociceptive pathway [4]. According to the migraine pathology, trigeminal ganglion provides sensory innervations with axons originating in $5 \mathrm{HT} 1 \mathrm{~B}$ and $5 \mathrm{HT} 1 \mathrm{D}$ receptors. The reduction of the vertigo symptoms in anti-migraine treatment is probably due to the inhibition of vascular response created by migraine pathology [4]. Tryptophan depletion boosted dizziness, nausea, and the illusion of movement in controls to levels that approached those of migraineurs. Thus, the reduced brain serotonin activity may promote vestibule ocular disturbances during motion sickness and attacks of migraine [119]. The hyper excitability and increased responsiveness of neuronal system in migraine may develop or contribute other balance disorders.

\section{Narcolepsy, Cataplexy and Sleep disorders}

Narcolepsy and other sleep disorders can occur due to the dysfunction of orexinergic neurons [120] and in migraine patients as mentioned above. Orexin as a neuropeptide involves playing a critical role in narcolepsy which promotes wakefulness and inhibiting RAM sleep [73]. Moreover it has been said that dopamine, serotonin and cholinergic neurotransmitters dysfunction also contribute to the disorders [120]. Therefor lesion or any interference to these neurotransmitter tracks affects the wakefulness. In this line it can be suggested that narcolepsy, cataplexy and other sleep disorders can also be triggered or caused by the dysfunction of the neurotransmitter track [73] caused by SHNOP or migraine. Thus the neuro pathophysiologies of these disorders are highlighting the comorbidity between migraine and sleep disorders [121]. However, one study said that there was no association between migraine and narcolepsy [41]. But other study said that migraine prevalence was twofold to fourfold increase in the narcoleptic patients and amounted to $44.4 \%$ in women and $28.3 \%$ in men [122]. In this way it could be said that alterations of sleep-wake cycle in narcolepsy may give such statistical evidence of high prevalence of migraine in patients with narcolepsy.

\section{Tumor genesis}

Though there are cases of patients with pituitary adenoma presented with classical migraine [123], no history has been found of association between migraine and tumor genesis. But the increase synthesis of n NO and inflammatory mediators in pathophysiology of migraine can be proposed that the pathology might involve in tumor genesis. For instances NO was found to stimulate GH-secreting adenomas [124] and the inflammatory mediators had been identified as a factor that could induce the adenoma [125] and cancer [122]. In addition oxidative stress and low melatonin level in migraine would also contribute to the tumor genesis. Thus in this line it can clearly be suggested here that high pituitary blood flow carrying inflammatory mediators, $\mathrm{n} \mathrm{NO}$, e $\mathrm{NO}$ and their metabolites in migraine pathology can directly or indirectly induce or aggravate pituitary adenoma as well as other tumors in the susceptible cranial tissues exposed to the mediators.

\section{Cluster headaches}

Cluster headaches had been completely cured by the rhino logical surgical operation that had removed the nasal and sinus anomies [22-24] and relived paranasal hypoxia indicating its etiological origin from the rhinosinogenic base. In addition there are strong evidence of comorbidities between cluster headache and migraine [126]. In this back ground it can be assumed that pathophysiology explained for migraine using SHNOT/P might be a primary cause to trigger the cluster headache. However it must be considered that there are secondary causes for cluster headache as well [127].

\section{Sinus headache and migraine}

It is important to understand the differences between pathophysiology between sinus headache and migraine. It is because some may confuse still to understand SHNOP for migraine and sinusitis. In fact it has been proven that sinus headache and migraine headache has $78 \%$ of association [13].This may indicate a common sinus hypoxic pathophysiological influences for both conditions according to SHNOP. Furthermore it is highlighted that NO production is within a range from $10 \%$ to $20 \%$ of oxygen to the sinuses in migraine [128]. In addition high sinus $\mathrm{NO}$ level had been found to precipitate sinusitis [129]. But on the other hand sinus NO production is depressed in sinusitis due to low activation of NOS enzymes [130]. Moreover when oxygen concentration below $10 \%$ it may increase tendency to develop sinusitis. By contrast with symptoms of migraine, sinusitis is associated with fever, nasal discharge, post nasal drip and radiological findings of sinusitis [131]. But migraine does not have such symptoms and can present without radiological findings of sinusitis and has been diagnosed according to IHS criteria [132].

Conclusively this pathophysiological association between migraine and neurological disorders would provide important massage in the management of the disorders. For instances, avoiding extra neuronal current to central nervous system by preventing or ameliorating of the development of pathology of migraine would give some benefit in the management of neurological disorders.

\section{To complete the Migraine and Neurological Disorder Co-morbidity}

All migraine patients are not end up in epileptic or stroke or systemic sclerosis or other neurological disorders though some migraine patients may suffer from mild to moderate transient neurological symptoms such as balance disorder or drowsiness etc. This type of resistance to those disorders could be due to genetic stability and lack of neurovascular vulnerability such as less vascular involvement, non-trauma or lesions in the brain and lack of anomalies in brain tissue. In such stage migraine may be in the neurological disorders without influence to them. When such resistance is low or altered by some vulnerable factors, migraine can have bidirectional comorbidity or unidirectional comorbidity with the neurological disorders. Moreover it is obvious as seen in epidemiological evidence that neurological disorders are higher in CM (Chronic Migraine) and MA (Migraine with Aura) than in episodic and short periods of attack of migraine. This can be suggested that it is because the toxic effects of $\mathrm{n}$ NO metabolites, glutamate and calcium ion and prolonged neurotoxic effects to neuronal cells in CM attacks. Environmental factors that conspire to produce inefficient information processing in the circuits [133] can also be acquired after birth by various factors such as physical trauma, drugs, toxins and infections that can have an influence on the circuit and neural tissue to produce neurological illnesses [134]. Heterogenecity of neurological illnesses may also indicate these multi factorial causes that can mask co-morbidity between migraine and neurological disorders. It may be because they could damage the neuronal tracks more than what has been done by migraine pathophysiology. On the other hand patients with migraine pathophysiological they can present themselves to a physician without the symptoms of migraine headache but with other migraine symptoms [135]. This may be due to some reasons such as habituation of migraine headache [136], inter neuronal disconnection, lower neuronal threshold for headache, immaturity of neuronal system 
in childhood [137] and the lack or poor sensitivity to nitric oxide [138]. Therefore in neurological assessment of patients or history taking from them should not depend or limit on the migraine symptoms or its criteria to be diagnosis.

\section{SHNOT/P in the use of Neurological Health Services}

Patients with migraine or other neurological illnesses consult neurologists, psychiatrist neurosurgeons or physicians would be of benefit to recognize migraine and its association with neurological disorder on basis of SHNOT/P. According to the new explanation not only migraine co morbid with neurological illness but also other neurological disorders should be investigated for SHNOP by such expertise. This is because the pathophysiology of migraine due to SHNOT/P can also present without migraine headache and with other neurological illnesses therefore the following investigation will be more important to diagnose the SHNOP to plan out treatment and assessment of the prognosis of neurological disorders.

\section{Investigation for Diagnosis of SHNOT/P Induced Migraine}

\section{MRI or CT-Scan of the brain and paranasal sinuses}

It is important to verify anatomical anomalies and pathological conditions relevant to SHNOP. Up to now even in migraine patients both scans have been mainly used to exclude mainly brain pathology that can contribute or trigger migraine symptoms. According to the new hypothesis the following paranasal sinus pathology is reported to help the diagnosis of SHNOP or get the idea of anatomical anomalies $[22,23]$ that contribute to paranasal hypoxia and can be explained as three divided levels such as intra nasal, ostial and intra sinus.

In the first level the anomalies in the nasal cavity are such as concha bullosa, paradoxical turbinate, large middle turbinate, nasal septal deviation and stenosis of nasal cavity. Furthermore, deviation of the unseated process tip, nasal spur, uncinate bulla and Haller cells may affect sinus ventilation [22,23]. In the second level blockade of sinus ostia can be observed in oedema or inflammation induced by various factors such as hormone, stress and food. Furthermore anatomical anomalies- ostiomeatal complex obstruction and narrowing e.g. large pneumatized ethmoidal bullae and mechanical obstruction-polyps and mucus plug induced hypoxia in the sinus cavities $[22,23]$ contribute to blockade of the sinus ostia. In addition the polyps in the sinus cavity cause increased levels of hypoxia because it absorbs oxygen and leads to produce more s NO. Sinusitis can be identified as being brought on by a higher level of sNO which is the main cause for SHNOP pathology, and is also a positive finding because migraine has direct association with sinus headache [132]. In the third level, sinus hypoxia and increased surface area for sNO diffusion could also be observed in intra sinus anomalies such as highly pneumatized cavities, narrowing of the opening of sub cavities, mucosal and vascular abnormalities and increased number of intra sinus septa or diverticula [22,23].

However, normal healthily sinus cavity views would not exclude the SHNOP because it could develop due to mucosal oedema or inflammation that cannot be visualized. For instance, the mucosal changes (e.g.: edema) due to hormonal changes in females, cold environment, alcohol, electrostatic change, emotional excitability, subclinical level of increased bacterial flora could not be identified from the scan films. In addition, high sNO can also keep sinuses in a clear state because anti-microbial action of $n$ NO [139]. On the other hand nasal and paranasal oedema may be due to parasympathetic hyper activity in migraine [140]. In psychiatric patients, the oedema induced by the neural effect can be reduced or normalized by tricycle antidepressants [141] or other drugs and reduces stress stage. Therefore such clinical events or state and clinical history that affects or paranasal hypoxia or parasympathetic tone should be considered in the clinical setup comparing the knowledge of the pathophysiology of migraine based on SHNOP.

Nasal and sinus endoscopy would help to identify some pathological conditions and anomalies. Furthermore according to the SHNOT ,sinus and nasal NO level would directly help to get information of a high level of sNO but it also varies with time due to some migraine trigger factors that would not have existed at the time of investigation. Moreover, moderate levels of the increase of sNO would not support a negative diagnosis because large diffusible vulnerable surface areas in the nasal cavity for $\mathrm{s} \mathrm{NO}$ and length of obstructive time in the cavity would facilitate diffusion of more s NO to develop migraine or SHNOP.

\section{Clinical Application and Limitation}

\section{New therapy for neurological disorders}

SHNOP as a cause or aggravator pathology of other neurological disorders directs us to plan a new strategy for the treatment of such neurological disorders that can be achieved by reducing the neurovascular impulse generation at the sinorhinological base. For instance, this therapy would help to prevent or reduce the aggravation of the hemorrhagic and ischemic stroke; ischemia induced mono neuropathy, venous thrombosis, beginning intracranial hypertension, empty Sella syndrome and tumors. Furthermore it would reduce the number of attacks of epilepsy ,narcolepsy, vestibular migraine ,motion sickness that are based on SHNOT/P or it's association. In addition sino rhinogenic pathology/SHNOP can be proposed for some other neurological disorders because the trigeminal neuronal network in the central nervous system is extensively interconnected with many other important neural structures through direct and indirect ways. Therefore the identification of migraine pathology /SHNOP or the early stages of its pathology which underlines neurological illness in an individual patient is extremely important.

Abolishing the inducement of paranasal sinus NOS: This could be brought on by three methods.

Adjustment of life style: Adequate sleep, Lack of stress and avoidance of emotional breakdowns and many other trigger factors of migraine would help to reduce nasal and sinus mucosal oedema. Interestingly cold weather or food or places (e.g. under a fan, air conditioned room or bus, cold wind) and body heat loss due to inadequate covering of body surface by cloth, cold bath, open body during the sleep that would contribute to induce parasypathatic activity via hypothalamus directly leading to nasal mucosal oedema or inflammation. This in turn induces higher production of $\mathrm{sNO}$ in the sinus cavity. Whereas hot treatment would temporarily in the environment also contribute reflex vasodilatation leading to nasal and sinus mucosal swelling. Therefore avoidance of these migraine triggers and cold stimulating agents or place or habit would help in the management of extra production of $\mathrm{sNO}$ in susceptible persons according to SHNOP.

Medical treatment: Medical therapies suppress the pathology that develops the hypoxia in the sinus. It includes anti-inflammatory therapy [anti-histamine, steroid therapy, non-steroidal anti-inflammatory drugs (NSAID)], vasoconstrictor drugs (intranasal sumatriptan, oxymetazoline) and diuretics (frusemide) they will also improve sinus ventilation by reducing the oedema or inflammation, and decrease 
the production of excess sNO induced by the hypoxia. Furthermore neurogenic inflammation in migraine patients could be reduced by the anti-inflammatory therapy and triptan. The latter group of drugs inhibits both vaso dilatation and neurogenic plasma extravasations. Most of these treatments is currently used in the medical management of migraine.

Standardized surgical treatment: Two surgical techniques for migraine and cluster headache have been suggested that applied will be effective in the SHNOP base psychiatric disorder or the susceptibility to aggravate those illnesses which are the Norvak Technique and the Bonoccorsi P Technique. Former includes more conservative treatment with septal correction, resection of middle concha, and ethmoidectomy on the ipsilateral migraine side. The latter technique is more radical, including septal correction, ethmoidectomy, sphenoidectomy and resection of the middle concha [22-24].

\section{The failure Rate of Surgical Treatment}

The failure rate of surgical treatment can be suggested due to many factors such as intact continuous activation of the trigeminal sensory nerve by dsNO in the vulnerable mucosa, a practical difficulty to manipulate the sinus ostia or sinus track or sinus cavity to normalize sNO levels, an inadequate or unskilled surgical approach, post-surgical complications (hypoxia to the sinuses or growth of the vulnerable new contact surface area, infection), lack of postoperative care , ,In addition it may be due to neuro pathological factors such as time taken for the recovery CNS pathology (e.g. Deficit central neurotransmitters levels, receptor changes and neural track dysfunction), a significant neuronal damage ,degeneration genetic vulnerability and central sensitization.

\section{Control of Central Pathophysiology of Neurological Disorders at Central Level}

This hypothesis does not propose that the above management is the only plan for neurological disorders that are mainly caused by SHNOP. It is because other factors for neurological disorder and migraine that will exist lifelong if it is not be treated well. Therefore, drug treatment and other therapy for the neurological illness should be continued with relevant guideline if necessary.

\section{Summary}

Migraine and neurological disorders are chronic recurrent, associated with significant morbidity, important impairment in daily functioning, and poor quality of life. Moreover the presence of SHNOP may contribute to develop neurological disorders or migraine, which is supported by many findings in both epidemiological evidence and pathophysiology of migraine and neurological disorders, and physiological actions of NO molecule. Migraine patients with other neurological disorders comorbidity are evident and no hopeful treatment exist mainly due to unknown exact etiology of migraine pathophysiology. Sinus hypoxic nitric oxide Theory for migraine could be considered to explain the relation or association for migraine and some neurological disorders and the therapeutic measures can be also introduced both preventive and curative treatment aspects. The existence of pathological process of SHNOP could take place in both patients with aura and non-aura migraine headache and even it could happen in person without headache among the normal population. Therefore different neurological presentations due to the consequence of chronicalization of neuro pathological effects could exist or have taken place even when they did not have experience of migraine attack earlier.
This in turn directs us to take early steps to prevent such neurological diseases other than migraine by detecting, investigation and diagnosis of migraine or SHNOP and impress the important of the application of medical or surgical approach or adjustment of life events on sinorhinological based theory. Finally SHNOT induced neurological condition seems to be more frequently found in the patients, who could be suggested as a major considerable pathophysiology contributed too many neurological disorders. Early steps to treatment for reducing the development or aggravation of SHNOP would help to ameliorate pathological factors that may associate or influence to aggravate or give rise some neurological illness through the extra or unnecessary neuron vascular impulse generation at sinorhinological based and progression of the pathological effect due to the pathology in the central nervous system so that it could prevent the pathophysiological processes that induce or contribute to cause neurological illnesses or to aggravate their pathophysiology.

\section{Conclusion}

Prevention and control of the excess or unnecessary impulse generation and neurovascular activation primarily in sinorhinological areas could be done by medical or surgical approach or adjustment of life events for the benefit of avoidance or prevent neuropathology affecting to cause or aggravate the neurological illnesses. However lack of knowledge of diagnosis for sinorhinogenic impulse generation for migraine and neurological disorders exists. Apart from the existing hypotheses for neurological disorders this SHNOP is suggested as a main or an additional etiological cause or aggregative factor for the neurological disorders and the comorbidity. Any how this article doesn't poise that SHNOT is the only cause of almost all neurological disorders. But sNO could be used here to explain the contribution or association of migraine pathophysiology and some neurological disorder comorbidity with migraine as well as development or aggravation of some neurological condition or disorders. Conclusively this review article has the following advantages. (a) It provides a pathophysiological link between migraine and neurological disorders. (b) It offers scope for sinorhinogenic based treatment and approach for migraine and some neurological disorders. (c) It provides a better understanding of newly proposed medical and surgical treatment for neurological disorders. (d) It provides and opens a completely new approach to novel pathophysiology for some neurological disorders. (e) It offers scope for primary prevention of the neurological disorders. (f) It provides information of a main cause or contributory factor for aggravation of existing neurological illnesses. (g) It provides a plausible explanation on why not all patients with migraine develop neurological disorders and associated different presentations. (h) It can be used to understand other hypotheses that are used to explain the pathology of different neurological disorders, migraine and neurological disorder -morbidity. (i) Finally it offers a novel coherent picture how sino rhino logical pathophysiology of migraine influences on its co-morbid neurological disorders and some other neurological disorders.

The value of such a scientific explanation and treatment cannot be underestimated. Leaving aside or attempting to ignore SHNOT/P among the pathophysiological hypotheses of the neurological illnesses seems to be a marked deficient and inaccurate neuro scientific approach in the field of neuroscience. What this article does offer is a naval perspective on many major factors in neurological disorders and suggests that SHNOT/P should receive much more attention and consideration as a potential causal and aggregative agent in the development of neurological disorders or their severity. However the sino rhino logical abnormalities and its etiology for the neurological 
Citation: Bandara SMR, Jayarathna DGAI, Thenakoon S, Senananayaka KJ (2014) Migraine and Neurological Disorders Comorbidity-Consideration of Sinus Hypoxic Nitric Oxide Theory for Migraine. J Neurol Disord 2: 175. doi:10.4172/2329-6895.1000175

disorders can cause diagnosis dilemma. Therefore clinicians should be aware of the possibility of these presentations arising from para nasal sinus or nasal pathology. Therefore it should receive comprehensive sino rhino logical examination and evaluation. Nasal endoscopy and paranasal sinus view of CT or MRI scans are good diagnostic tools.

The sinorhinological approach is not already used to treat nurological disorders in clinical practice though it has been successfully considered as treatment for migraine by Norvak Technique and Bonoccorsi $\mathrm{P}$ $[22,23]$. I feel that the favorable clinical profile of sinorhinological approach, together with lack of major contraindications, suggest that the sinorhinological management with existing therapy should be regarded as a first-line treatment for the prevention or reducing the aggravation of both migraine and its comorbid neurological illnesses and other SHNOP related neurological disorders. However long term consequences of the surgical and medical intervention of sinorhinological approach for migraine and neurological disorder co-morbidity and other neurological disorders should be studied further and investigated by clinical trial. If the surgical and medical based management of sinorhinological therapy for the neurological disorders is more effective, this could open a completely new approach to more than $10-40 \%$ of the world population who suffer from various neurological disorders based on sinorhinological aetiology from minimum to sever form and to get rid of individual suffering. Moreover theses involve in primary prevention of such neurological disorders and thus it will also reduce the social burden.

\section{References}

1. Stovner LJ, Zwart JA, Hagen K, Terwindt GM, Pascual J (2006) Epidemiology of headache in Europe. Eur $\mathrm{J}$ Neurol 13: 333-345.

2. Kurth T, Chabriat H, Bousser MG (2012) Migraine and stroke: a complex association with clinical implications. Lancet Neurol 11: 92-100.

3. Davies PT, Panayiotopoulos CP (2011) Migraine triggered seizures and epilepsy triggered headache and migraine attacks: a need for re-assessment. $\mathrm{J}$ Headache Pain 12: 287-288.

4. Conforto AB, Lois LA, Amaro E Jr, Paes AT, Ecker C, et al. (2010) Migraine and motion sickness independently contribute to visual discomfort. Cephalalgia 30: 161-169.

5. Neuhauser H, Leopold M, von Brevern M, Arnold G, Lempert T (2001) The interrelations of migraine, vertigo, and migrainous vertigo. Neurology 56: 436441.

6. Balaban CD, Jacob RG, Furman JM (2011) Neurologic bases for comorbidity of balance disorders, anxiety disorders and migraine: neurotherapeutic implications. Expert Rev Neurother 11: 379-394.

7. Stanley TV (2002) Idiopathic intracranial hypertension presenting as hemiplegic migraine. Acta Paediatr 91: 980-982.

8. Shuu-Jiun W, Ping-Kun C, Jong-Ling F (2010) Comorbidities of Migraine. Front Neurol 1: 16

9. Pezzini A, Del Zotto E, Giossi A, Volonghi I, Costa P, et al. (2010) The migraineischemic stroke relation in young adults. Stroke Res Treat 2011: 304921.

10. Rogawski MA (2008) Common pathophysiologic mechanisms in migraine and epilepsy. Arch Neurol 65: 709-714.

11. Rathnasiri Bandara SM (2013) Paranasal sinus nitric oxide and migraine: a new hypothesis on the sino rhinogenic theory. Med Hypotheses 80: 329-340.

12. Cardell LO (2002) The paranasal sinuses and a unique role in airway nitric oxide production? Am J Respir Crit Care Med 166: 131-132.

13. Haight JS, Qian W, Daya H, Chalmers P, Zamel N (2000) Hypoxia depresses nitric oxide output in the human nasal airways. Laryngoscope 110: 429-433.

14. Schairer DO, Chouake JS, Nosanchuk JD, Friedman AJ (2012) The potential of nitric oxide releasing therapies as antimicrobial agents. Virulence 3: 271-279.

15. Lancaster JR Jr (1994) Simulation of the diffusion and reaction of endogenously produced nitric oxide. Proc Natl Acad Sci USA 91: 8137-8141.
16. Wood J, Garthwaite J (1994) Models of the diffusional spread of nitric oxide: implications for neural nitric oxide signalling and its pharmacological properties. Neuropharmacology 33: 1235-1244.

17. Ganon WF (2003) Review of medical physiology. India: 21st ed. The McGrawHill companies 3: 43-48.

18. Pacher P, Beckman JS, Liaudet $L$ (2007) Nitric oxide and peroxynitrite in health and disease. Physiol Rev 87: 315-424.

19. Strecker 1, Dux M, Messlinger K (2002) Nitric oxide releases calcitonin-generelated peptide from rat dura mater encephali promoting increases in meningea blood flow. J Vasc Res 39: 489-496.

20. Andersson JA, Cervin A, Lindberg S, Uddman R, Cardell LO (2002) A decrease in maxillary sinus pressure, as seen in upper airway allergy or infection, results in an increase in upper airway nitric oxide levels. Acta Otolaryngol 122: 520523.

21. Bonaccorsi P (1998) Primary headache compared with idio pathic rhinogenic headache: the actual diagnostic misunderstandings. Rhinology Suppl. L, 1998. Abstract book. 12th Congress European Rhinologic Society including the VII the ISIAN, Amsterdam, 63: 19-22.

22. Norvak VJ (1994) Pathogensis and surgical treatment of neurovascular primay headaches. The croatian medical association. Rejeka Med 1: 19-22.

23. Novak VJ, Novoselac M, Muller W (1988) Pathogenesis and surgical treatment of migraine attacks caused by weather(f6hn), menstruation, stress and nutrition. Rhinology Suppl 1. Abstract book. 12th Congress European Rhinologic Society including the VIIth ISIAN, Amsterdam 62: 19-22.

24. Welge-Lüssen A, Hauser R, Probst R (1996) 3-year follow-up after endonasa microscopic paranasal sinus surgery in migraine and cluster headache. Laryngorhinootologie 75: 392-396.

25. Maizels M, Scott B, Cohen W, Chen W (1996) Intranasal lidocaine for treatment of migraine: a randomized, double-blind, controlled trial. JAMA 276: 319-321.

26. van der Kuy PH, Merkus FW, Lohman JJ, ter Berg JW, Hooymans PM (2002) Hydroxocobalamin, a nitric oxide scavenger, in the prophylaxis of migraine: an open, pilot study. Cephalalgia 22: 513-519.

27. Cady RK, Sheftell F, Lipton RB, O'Quinn S, Jones M, et al. (2000) Effect of early intervention with sumatriptan on migraine pain: retrospective analyses of data from three clinical trials. Clin Ther 22: 1035-1048.

28. Stankewitz A, Aderjan D, Eippert F, May A (2011) Trigeminal nociceptive transmission in migraineurs predicts migraine attacks. J Neurosci 31: 19371943.

29. Hummel T, Doty RL, Yousem DM (2005) Functional MRI of intranasal chemosensory trigeminal activation. Chem Senses 30 Suppl 1: i205-206.

30. Lundberg JO (2008) Nitric oxide and the paranasal sinuses. Anat Rec (Hoboken) 291: 1479-1484

31. Juhász G, Zsombók T, Gonda X, Bagdy G (2004) Nitroglycerin-induced headaches. Orv Hetil 145: 2323-2328.

32. Martin L, Jens PD, Martin F (2011) Clinical relevance of cortical spreading depression in neurological disorders: migraine, malignant stroke, subarachnoid and intracranial hemorrhage, and traumatic brain injury $\mathrm{J}$ Cereb Blood Flow Metab. 31: 17-35.

33. Belcastro V, Striano P, Kasteleijn-Nolst Trenité DG, Villa MP, Parisi P (2011) Migralepsy, hemicrania epileptica, post-ictal headache and "ictal epileptic headache": a proposal for terminology and classification revision. J Headache Pain 12: 289-294.

34. Lipton RB, Ottman R, Ehrenberg BL, Hauser WA (1994) Comorbidity of migraine: the connection between migraine and epilepsy. Neurology 44: S28-32.

35. Ottman R, Lipton RB (1994) Comorbidity of migraine and epilepsy. Neurology 44: 2105-2110

36. Bellini B, Arruda M, Cescut A, Saulle C, Persico A, et al. (2013) Headache and comorbidity in children and adolescents. J Headache Pain 14: 79.

37. Kittner SJ, Stern BJ, Wozniak M, Buchholz DW, Earley CJ, et al. (1998) Cerebral infarction in young adults: the Baltimore-Washington Cooperative Young Stroke Study. Neurology 50: 890-894.

38. Kittner SJ, Stern BJ, Wozniak M, Buchholz DW, Earley CJ, et al. (1998) Cerebral infarction in young adults: the Baltimore-Washington Cooperative Young Stroke Study. Neurology 50: 890-894. 
Citation: Bandara SMR, Jayarathna DGAI, Thenakoon S, Senananayaka KJ (2014) Migraine and Neurological Disorders Comorbidity-Consideration of Sinus Hypoxic Nitric Oxide Theory for Migraine. J Neurol Disord 2: 175. doi:10.4172/2329-6895.1000175

39. Kurth T, Slomke MA, Kase CS, Cook NR, Lee IM, et al. (2005) Migraine, headache, and the risk of stroke in women: a prospective study. Neurology 64: $1020-1026$

40. Dahmen N, Kasten M, Wieczorek S, Gencik M, Epplen JT, et al. (2003) Increased frequency of migraine in narcoleptic patients: a confirmatory study. Cephalalgia 23: 14-19.

41. Ressler KJ, Nemeroff CB (2000) Role of serotonergic and noradrenergic systems in the pathophysiology of depression and anxiety disorders. Depress Anxiety 12 Suppl 1: 2-19.

42. Pietrobon D (2010) CaV2.1 channelopathies. Pflugers Arch 460: 375-393.

43. Elliott D (2008) Migraine and stroke: current perspectives. Neurol Res 30: $801-$ 812

44. Mauskop A (2012) Nonmedication, alternative, and complementary treatments for migraine. Continuum (Minneap Minn) 18: 796-806.

45. Thomas DJ (2005) Migraine and ischaemic stroke. BMJ 330: 54-55.

46. Togha M, Rahmat Jirde M, Nilavari K, Ashrafian H, Razeghi S, et al. (2008) Cinnarizine in refractory migraine prophylaxis: efficacy and tolerability. A comparison with sodium valproate. J Headache Pain 9: 77-82.

47. Togha M, Ashrafian H, Tajik $P$ (2006) Open-label trial of cinnarizine in migraine prophylaxis. Headache 46: 498-502

48. Reploeg MD, Goebel JA (2002) Migraine-associated dizziness: patient characteristics and management options. Otol Neurotol 23: 364-371.

49. Lassen LH, Ashina M, Christiansen I, Ulrich V, Grover R, et al. (1998) Nitric oxide synthase inhibition: a new principle in the treatment of migraine attacks. Cephalalgia 18: 27-32.

50. Thomsen LL, Olesen $\mathrm{J}$ (2001) Nitric oxide in primary headaches. Curr Opin Neurol 14: 315-321.

51. Mula M, Hesdorffer DC, Trimble M, Sander JW (2009) The role of titration schedule of topiramate for the development of depression in patients with epilepsy. Epilepsia 50: 1072-1076

52. McNeil GN, Shaw PK, Dock DS (1982) Substitution of atenolol for propranolo in a case of propranolol-related depression. Am J Psychiatry. 139: 1187-1188.

53. Russell MB, Ducros A (2011) Sporadic and familial hemiplegic migraine: pathophysiological mechanisms, clinical characteristics, diagnosis, and management. Lancet Neurol 10: 457-470.

54. Ophoff RA, DeYoung J (2001) Hereditary Vascular Retinopathy, Cerebroretinal Vasculopathy, and Hereditary Endotheliopathy with Retinopathy, Nephropathy, and Stroke Map to a Single Locus on Chromosome 3p21.1-p21.3. Am J Hum Genet 69: 447-453.

55. Chemelli RM, Willie JT, Sinton CM, Elmquist JK, Scammell T, et al. (1999) Narcolepsy in orexin knockout mice: molecular genetics of sleep regulation. Cell 98: 437-451.

56. Thannickal TC, Moore RY, Nienhuis R, Ramanathan L, Gulyani S, et al. (2000) Reduced number of hypocretin neurons in human narcolepsy. Neuron 27: 469474.

57. Rathnasiri BMR, Selwarathnum S (2012) Sino rhinogenic anomalies mimic of neurological illnesses. Report, Teaching Hospital Kandy, Sri Lanka.

58. Cahill CM, Murphy KC (2004) Migraine: another headache for psychiatrists? Br J Psychiatry 185: 191-193.

59. Sandkuhler J, Fu QC, Zimmermann M, Spinal pathway mediating tonic or stimulation-produced descending inhibition from the periaqueductal gray or nucleus raphe magnus are separate in the cat. J Neurophysiol.

60. Waselus M, Valentino RJ, Van Bockstaele EJ (2011) Collateralized dorsa raphe nucleus projections: a mechanism for the integration of diverse functions during stress. J Chem Neuroanat 41: 266-280.

61. Fields HL, Heinricher MM (1985) Anatomy and physiology of a nociceptive modulatory system. Philos Trans R Soc Lond B Biol Sci 308: 361-374.

62. Antonaci F, Nappi G, Galli F, Manzoni GC, Calabresi P, et al. (2011) Migraine and psychiatric comorbidity: a review of clinical findings. J Headache Pain 12: 115-125.

63. Stahl SM (2000) Essential psychopharmacology. Cambridge University press, UK, 863-881.
64. Seo D, Patrick CJ, Kennealy PJ (2008) Role of Serotonin and Dopamine System Interactions in the Neurobiology of Impulsive Aggression and its Comorbidity with other Clinical Disorders. Aggress Violent Behav 13: 383-395.

65. Jung AC, Staiger T, Sullivan M (1997) The efficacy of selective serotonin reuptake inhibitors for the management of chronic pain. J Gen Intern Med 12 384-389.

66. Fink KB, Göthert M (2007) 5-HT receptor regulation of neurotransmitter release. Pharmacol Rev 59: 360-417.

67. Gupta R, Pathak R, Bhatia MS, Banerjee BD (2009) Comparison of oxidative stress among migraineurs, tension-type headache subjects, and a control group. Ann Indian Acad Neurol 12: 167-172.

68. Martinez F (1993) Migraineurs had lower levels of noradrenaline in plasma and cerebrospinal fluid during attacks in one study. NeurolNeurosurg Psychiatry 56:1119-21.

69. Ciancarelli I, Tozzi-Ciancarelli MG, Di Massimo C, Marini C, Carolei A (2003) Urinary nitric oxide metabolites and lipid peroxidation by-products in migraine. Cephalalgia 23: 39-42.

70. Stahl SM (2008) From circuits to symptoms in psychoparmacology. Essential psychopharmacology (3rdedtn). Cambridge University press, UK 490-499.

71. Cevoli S, Giannini G, Favoni V, Pierangeli G, Cortelli P (2012) Migraine and sleep disorders. Neurol Sci 33 Suppl 1: S43-46.

72. Dalkvist J, Ekbom K, Waldenlind E (1984) Headache and mood: a time-series analysis of self-ratings. Cephalalgia 4: 45-52.

73. Morgane PJ, Galler JR, Mokler DJ (2005) A review of systems and networks of the limbic forebrain/limbic midbrain. Prog Neurobiol 75: 143-160.

74. Claustrat B, Brun J, Garry P, Roussel B, Sassolas G (1986) A once-repeated study of nocturnal plasma melatonin patterns and sleep recordings in six normal young men. J Pineal Res 3: 301-310.

75. Lee MG, Hassani OK, Jones BE (2005) Discharge of identified orexin/ hypocretin neurons across the sleep-waking cycle. J Neurosci 25: 6716-6720.

76. Monti JM, Jantos $H(2008)$ The roles of dopamine and serotonin, and of their receptors, in regulating sleep and waking. Prog Brain Res 172: 625-646.

77. Stahl SM (2008) Anxiety disorders and anxiolytics. Essential psychopharmacology (3rdedtn) Cambridge University press, UK. 749-799.

78. Woolf CJ (2011) Central sensitization: implications for the diagnosis and treatment of pain. Pain 152: S2-15.

79. Gelder M, Harrison P, Crown P (2006) Shorter Oxford Text book of psychiatric. 2006 Oxford University press, India. 531-561.

80. Gartside SE, Hajós-Korcsok E, Bagdy E, Hársing LG Jr, Sharp T, et al. (2000) Neurochemical and electrophysiological studies on the functional significance of burst firing in serotonergic neurons. Neuroscience 98: 295-300.

81. Sicuteri F (1976) Hypothesis: migraine, a central biochemical dysnociception Headache 16: 145-159.

82. Luo ZD, Cizkova D (2000) The role of nitric oxide in nociception. Curr Rev Pain 4: 459-466.

83. Read SJ, Smith MI, Hunter AJ (1997)Enhanced nitric oxide release during cortical spreading depression following infusion of glyceryl trinitrate in the anaesthetized cat.Cephalalgia 17:159-165.

84. Strecker T, Messlinger K (2003) [Neuropeptide release in the dura mater encephali in response to nitric oxide--relevance for the development of vascular headaches?]. Schmerz 17: 179-184.

85. Lorrain DS, Hull EM (1993) Nitric oxide increases dopamine and serotonin release in the medial preoptic area. Neuroreport 5: 87-89.

86. Dodd ML, Klos KJ, Bower JH, Geda YE, Josephs KA, et al. (2005) Pathological gambling caused by drugs used to treat Parkinson disease. Arch Neurol 62 : 1377-1381.

87. Kanai AJ, Strauss HC, Truskey GA (1995) Shear Stress Induces ATPIndependent Transient Nitric Oxide Release From Vascular Endothelial Cells, Measured Directly With a Porphyrinic Microsensor Circulation Research 77 284-293.

88. Kang Y, Dempo Y, Ohashi A, Saito M, Toyoda H, et al. (2007) Nitric oxide activates leak $\mathrm{K}+$ currents in the presumed cholinergic neuron of basa forebrain. J Neurophysiol 98: 3397-3410. 
Citation: Bandara SMR, Jayarathna DGAI, Thenakoon S, Senananayaka KJ (2014) Migraine and Neurological Disorders Comorbidity-Consideration of Sinus Hypoxic Nitric Oxide Theory for Migraine. J Neurol Disord 2: 175. doi:10.4172/2329-6895.1000175

Page 12 of 13

89. Förstermann U, Closs El, Pollock JS, Nakane M, Schwarz P, et al. (1994) Nitric oxide synthase isozymes. Characterization, purification, molecular cloning, and functions. Hypertension 23: 1121-1131.

90. Li H, Wallerath T, Münzel T, Förstermann U (2002) Regulation of endothelialtype NO synthase expression in pathophysiology and in response to drugs. Nitric Oxide 7: 149-164.

91. Peres MF, Sanchez del Rio M, Seabra ML, Tufik S, Abucham J, et al. (2001) Hypothalamic involvement in chronic migraine. J Neurol Neurosurg Psychiatry 71: 747-751.

92. Acuña-Castroviejo D, Escames G, Macías M, Muñóz Hoyos A, Molina Carballo A, et al. (1995) Cell protective role of melatonin in the brain. J Pineal Res 19: 57-63.

93. Baydas G, Reiter RJ, Akbulut M (2005) Melatonin inhibits neural apoptosis induced by homocysteine in hippocampus of rats via inhibition of cytochrome $c$ translocation and caspase- 3 activation and by regulating pro- and antiapoptotic protein levels. Neuroscience. 135:879-886.

94. Anderman F (1987) Clinical features of migraine-epilepsy syndromes. In: Anderman F, Lugaresi E, editors. Migraine and epilepsy. Boston: Butterworths; 30.

95. Bianchin MM, Londero RG, Lima JE, Bigal ME (2010) Migraine and epilepsy: a focus on overlapping clinical, pathophysiological, molecular, and therapeutic aspects. Curr Pain Headache Rep 14: 276-283.

96. Imamura K, Takeshima T, Fusayasu E, Nakashima K (2008) Increased plasma matrix metalloproteinase-9 levels in migraineurs. Headache 48: 135-139.

97. Moskowitz MA, Kurth T (2007) Blood vessels, migraine, and stroke. Stroke 38 3117-3118.

98. Colombo B, Dalla Libera D, Comi G (2011) Brain white matter lesions in migraine: what's the meaning? Neurol Sci 32 Suppl 1: S37-40.

99. Dalkara T, Nozari A, Moskowitz MA (2010) Migraine aura pathophysiology: the role of blood vessels and microembolisation. Lancet Neurol 9: 309-317.

100.Bartleson JD (1984) Transient and persistent neurological manifestations of migraine. Stroke 15: 383-386.

101. Nóbrega JC, Siqueira SR, Siqueira JT, Teixeira MJ (2007) Diferential diagnosis in atypical facial pain: a clinical study. Arq Neuropsiquiatr 65: 256-261.

102. Allegri $P$, Rissotto R, Herbort CP, Murialdo $U$ (2011) CNS diseases and uveitis J Ophthalmic Vis Res 6: 284-308.

103. Susan Duty, Peter Jennern (2011) Animal models of Parkinson's disease: a source of novel treatments and clues to the cause of the disease. British Journal of Pharmacology, 164: 1357-1391.

104. van Hilten JJ (1992) The migraine-dopamine link: do migraine and Parkinson's disease coexist? Clin Neurol Neurosurg 94 Suppl: S168-170.

105. Mathew NT, Ravishankar K, Sanin LC (1996) Coexistence of migraine and idiopathic intracranial hypertension without papilledema. Neurology 46: 12261230.

106. Walker RW (2001) Idiopathic intracranial hypertension: any light on the mechanism of the raised pressure? J Neurol Neurosurg Psychiatry 71: 1-5.

107. Strazielle N, Khuth ST, Murat A (2003) Pro-inflammatory cytokines modulate matrix metalloproteinase secretion and organic anion transport at the bloodcerebrospinal fluid barrier. J Neuropathol Exp Neurol. 62: 1254-1264.

108. Ireland B, Corbett JJ, Wallace RB (1990) The search for causes of idiopathic intracranial hypertension. A preliminary case-control study. Arch Neurol 47: 315-320.

109. Bonneville JF, Dietmann JL (1981) Intrasellar pathology. In: Radiology of the Sella turcica. Springer Verlag, New York 89-126.

110. Chang HS, Nakagawa H (2003) Hypothesis on the pathophysiology of syringomyelia based on simulation of cerebrospinal fluid dynamics. J Neurol Neurosurg Psychiatry 74: 344-347.

111. GARDNER WJ, ANGEL J (1958) The cause of syringomyelia and its surgical treatment. Cleve Clin Q 25: 4-8.

112. Heiss JD, Snyder K, Peterson MM, Patronas NJ, Butman JA, et al. (2012) Pathophysiology of primary spinal syringomyelia. J Neurosurg Spine 17: 367-380.

113. Estey A, Lynch T, Lim RK (2009) Cerebral sinovenous thrombosis masquerading as migraine: a case report. Pediatr Emerg Care 25: 174-176.
114. Sasidharan PK (2012) Cerebral vein thrombosis misdiagnosed and mismanaged. Thrombosis 2012: 210676.

115. Guzik TJ, West NE, Pillai R, Taggart DP, Channon KM (2002) Nitric oxide modulates superoxide release and peroxynitrite formation in human blood vessels. Hypertension 39: 1088-1094.

116. Kister I, Munger KL, Herbert J, Ascherio A (2012) Increased risk of multiple sclerosis among women with migraine in the Nurses' Health Study II. Mult Scler 18: $90-97$

117. Hernández-Pedro NY, Espinosa-Ramirez G, de la Cruz VP, Pineda B, Sotelo $J$ (2013) Initial immunopathogenesis of multiple sclerosis: innate immune response. Clin Dev Immunol 2013: 413465

118. Drummond PD (2005) Effect of tryptophan depletion on symptoms of motion sickness in migraineurs. Neurology 65: 620-622.

119. Billiard M (2008) Narcolepsy: current treatment options and future approaches. Neuropsychiatr Dis Treat 4: 557-566.

120. Tsujino N, Sakurai T (2009) Orexin/hypocretin: a neuropeptide at the interface of sleep, energy homeostasis, and reward system. Pharmacol Rev 61: 162 176.

121.DMKG Study Group (2003) Migraine and idiopathic narcolepsy--a case-control study. Cephalalgia 23: 786-789.

122. Lee AH (1990) Pituitary adenoma causing classical migraine. Br J Neurosurg 4: $347-348$.

123. Onishi K, Kamida T, Momii Y, Abe T, Fujiki M (2014) The clinical and pathological significance of nitric oxide synthase in human pituitary adenomas: a comparison with MIB-1. Endocrine 46: 154-159.

124. Hu B, Elinav E, Huber S, Booth CJ, Strowig T, et al. (2010) Inflammationinduced tumorigenesis in the colon is regulated by caspase-1 and NLRC4. Proc Natl Acad Sci U S A 107: 21635-21640.

125. Rakoff-Nahoum S (2006) Why Cancer and Inflammation?. Yale J Biol Med. 79: $123-130$.

126.Zidverc-Trajkovic JJ, Pekmezovic TD, Sundic AL, Radojicic AP, Sternic NM (2011) Comorbidities in cluster headache and migraine. Acta Neurol Belg 111: 50-55.

127. Favier I, van Vliet JA, Roon KI, Witteveen RJ, Verschuuren JJ, et al. (2007) Trigeminal autonomic cephalgias due to structural lesions: a review of 31 cases. Arch Neurol 64: 25-31.

128. Naraghi M, Deroee AF, Ebrahimkhani M, Kiani S, Dehpour A (2007) Nitric oxide: a new concept in chronic sinusitis pathogenesis. Am J Otolaryngol 28 334-337.

129. Kaliner MA, Osguthorpe JD, Fireman P, Anon J, Georgitis J, et al. (1997) Sinusitis: bench to bedside. Current findings, future directions. J Allergy Clin Immunol 99: S829-S848.

130. Lundberg JO, Weitzberg E, Cole JA, Benjamin N (2004) Nitrate, bacteria and human health. Nat Rev Microbiol 2: 593-602.

131. Silberstein SD, Olesen J, Bousser MG, Diener HC, Dodick D, et al. (2005) The International Classification of Headache Disorders, 2nd Edition (ICHDII)--revision of criteria for 8.2 Medication-overuse headache. Cephalalgia 25: 460-465.

132. Habib M (2000) The neurological basis of developmental dyslexia: an overview and working hypothesis. Brain 123 Pt 12: 2373-2399.

133. Menon DK, Schwab K, Wright DW, Maas Al; Demographics and Clinica Assessment Working Group of the International and Interagency Initiative toward Common Data Elements for Research on Traumatic Brain Injury and Psychological Health (2010) Position statement: definition of traumatic brain injury. Arch Phys Med Rehabil 91: 1637-1640.

134.Lance JW (1978) Mechanism and Management of Headache. (3rdedtn). Butterworths, Boston, USA.

135. Siniatchkin M, Kropp P, Gerber WD (2003) What kind of habituation is impaired in migraine patients? Cephalalgia 23: 511-518.

136. Rasquin-Webera A (1999) P E Hyman's Cucchiara. Childhood functional gastrointestinal disorders. Gut 45:II 60-II 68

137. Olesen J, Iversen HK, Thomsen LL (1993) Nitric oxide supersensitivity: a possible molecular mechanism of migraine pain. Neuroreport 4: 1027-1030. 
Citation: Bandara SMR, Jayarathna DGAI, Thenakoon S, Senananayaka KJ (2014) Migraine and Neurological Disorders Comorbidity-Consideration of Sinus Hypoxic Nitric Oxide Theory for Migraine. J Neurol Disord 2: 175. doi:10.4172/2329-6895.1000175

Page 13 of 13

138. Schreiber CP, Hutchinson S, Webster CJ, Ames M, Richardson MS, et al. (2004) Prevalence of migraine in patients with a history of self-reported or physician-diagnosed "sinus" headache. Arch Intern Med 164: 1769-1772.

139. Lundberg JO, Weitzberg E (1999) Nasal nitric oxide in man. Thorax 54: 947952.
140. Goadsby PJ, Lipton RB (1997) A review of paroxysmal hemicranias, SUNCT syndrome and other short-lasting headaches with autonomic feature, including new cases. Brain 120: 193-209.

141. Bendtsen L, Birk S, Kasch H, Aegidius K, Sørensen PS, et al. (2012) Reference programme: diagnosis and treatment of headache disorders and facial pain. Danish Headache Society, 2nd Edition, 2012. J Headache Pain 13 Suppl 1: S1-29. 